\title{
Análise microbiológica de frutas minimamente processadas servidas em uma Unidade de Alimentação e Nutrição
}

\section{Microbiological analysis minimally processed fruits Food and Nutrition Unit}

\author{
Analha Dyalla Feitosa Lins ${ }^{1}$, Cícera Gomes Cavalcante de Lisbôa ${ }^{2}$, Maria Suiane de Moraes ${ }^{3}$, Ana Caroline Fernandes \\ Sampaio ${ }^{4}$ Dannaya Julliethy Gomes Quirino
}

\begin{abstract}
Resumo: Produtos minimamente processados têm sido descrito como produtos manipulados, preparados, embalados e distribuídos, que passam por procedimentos como seleção, limpeza, lavagem, descascamento e corte que não comprometem suas características organolépticas e agreguem valor aos mesmos. Alguns desses procedimentos podem proporcionar lesões que resultam em aceleração da respiração, produção de etileno, senescência, amadurecimento, deterioração e uma contaminação microbiológica. Partindo desse pressuposto, esse trabalho tem como objetivo verificar as condições microbiológicas de mamão, melão, abacaxi e melancia minimamente processados, provenientes de uma Unidade de Alimentação e Nutrição de um município da Região do Cariri do Estado do Ceará. As análises de coliformes totais, termotolerantes e detecção de Salmonella sp, foram realizadas segundo os padrões e metodologias da Americam Public Health Association. Através dos resultados deste trabalho baseados na RDC No 12, de 2 de Janeiro de 2001 da Agência Nacional de Vigilância Sanitária, as quatro amostras de frutas apresentaram contagem $\geq 2,4 \times 10^{3} \mathrm{NMP} / \mathrm{g}$ para Coliformes Totais e termotolerantes e ausência de Salmonella $s p$. Sugere-se assim que sejam revistas as Boas Práticas de Fabricação (BPF), assim como a adoção de um Programa de Análise de Perigos e Pontos Críticos de Controle (APPCC) para garantir um produto de qualidade e seguro para o consumidor.
\end{abstract}

Palavras-chaves: Condições higiênico- sanitárias, Vegetais, Higienização, Boas Práticas de Fabricação.

Abstract: Minimally processed products have been described as products handled, prepared, packaged and distributed, passing through procedures such as screening, cleaning, washing, peeling and cutting that do not compromise their organoleptic characteristics and add value to them. Some of these procedures may provide injuries that result in acceleration of respiration ethylene production, senescence, maturation, decay and microbiological contamination. ethylene production, senescence, maturation, decay and microbiological contamination. Based on this assumption, this study aims to determine the microbiological conditions papaya, melon, pineapple and watermelon minimally processed, from a Power Unit Nutrition in a municipality in the State of Ceará Cariri Region. The analysis of total coliforms and thermotolerant and detect Salmonella sp, were performed according to the standards and methodologies of Americam Public Health Association. Through the results of this work based on the RDC No. 12, of 2 January 2001 the National Health Surveillance Agency, 4 samples showed fruit Count $\geq 2.4 \times 10^{3} \mathrm{MPN} / \mathrm{g}$ for total and coliforms thermotolerant and Salmonella $s p$. To suggest so review the Good Manufacturing Practices (GMP), and the adoption of a Hazard Analysis Program and Critical Control Points (HACCP) to ensure product quality and safe for the consumer.

Key words: Hygienic-sanitary conditions, Vegetables, Sanitation, Good Manufacturing Practices.

\footnotetext{
*Autor para correspondência

Recebido para publicação em 28/02/2015; aprovado em 10/10/2015

${ }^{1}$ Mestranda do Departamento de Engenharia Agrícola, Área de Armazenamento e Processamento de Produtos Agrícolas- UFCG-Universidade Federal de Campina Grande. E-mail: dyallalins@gmail.com

${ }^{2}$ Doutoranda do Departamento de Engenharia Agrícola, Área de Armazenamento e Processamento de Produtos Agrícolas- UFCG. E-mail:

livia.lisboa@ig.com.br

${ }^{3}$ Graduada em Tecnologia em Alimentos, Faculdade de Tecnologia- FATEC-CARIRI. E-mail: suiane-2009@hotmail.com

${ }^{4}$ Graduanda em Nutrição, Faculdade de Juazeiro do Norte- FJN. E-mail: carolinefersamp@ hotmail.com

${ }^{5}$ Graduanda em Nutrição, Faculdade de Juazeiro do Norte- FJN. E-mail: dannaya_gomes@yahoo.com
} 


\section{INTRODUÇÃO}

O Brasil é o terceiro maior produtor mundial de frutas, superado apenas por China e Índia (ANDRADE, 2012), assim, torna-se necessário e relevante evitar a contaminação dos frutos que pode ser iniciada na fase de plantio, quando há o contato com solo, água, fezes de animais, insetos e manipuladores; continuando durante as etapas de colheita, manuseio, transporte da matéria-prima até a indústria, durante processamento, finalizando-se no preparo do produto $\mathrm{e}$ exposição para o consumidor (ROMANICHEN et al., 2010).

Atualmente, o mercado de produtos frescos tem crescido de maneira significativa (ARVANITOYANNIS et al., 2009), destacando-se o segmento de produtos minimamente processados, que inclui operações simples como, seleção, lavagem, classificação, corte (fatiamento), sanitização, centrifugação, embalagem e refrigeração, mantendo ainda o frescor, a qualidade nutricional e sensorial do produto. Além desses aspectos o consumidor espera que esses alimentos sejam seguros e práticos (JACXSENS et al., 2010). No Brasil, o uso dos minimamente processados é recente, eles foram introduzidos nos anos 90 por empresas atraídas pelas novas tendências de mercado, envolvendo, principalmente, restaurantes, lanchonetes, redes de supermercados e hotéis (FAO, 2013).

A técnica minimamente processados apenas tenta desacelerar os fenômenos de senescência, recorrendo à técnicas que permitam também atrasar a inevitável alteração de aspecto, textura, flavour (sabor e aroma) e valor nutricional dos produtos, ao longo do tempo de armazenamento (RAMOS et al., 2013). Além disso, os danos os quais os produtos minimamente processados estão sujeitos durante sua manipulação proporcionam mudanças no metabolismo dos tecidos danificados que podem acelerar a respiração, produzir etileno, senescência, amadurecimento e deteriorar. A remoção da camada de epiderme também expõe os tecidos interiores a oxidação e escurecimento, favorecendo o aumento da perda de água e acesso mais fácil para infecção por microrganismos (FENNEMA, et al., 2010).

Todavia, ainda são poucos os conhecimentos sobre os aspectos microbiológicos dos produtos minimamente processados, da vulnerabilidade à contaminação e proliferação de microrganismos. Portanto, esse trabalho tem como objetivo verificar as condições higiênico-sanitária de mamão, melão, abacaxi e melancia minimamente processados em uma Unidade de Alimentação e Nutrição, com base na RDC N $^{\circ}$ 12, de 2 de Janeiro de 2001 da Agência Nacional de Vigilância Sanitária (ANVISA).

\section{MATERIAL E MÉTODOS}

\section{Coleta das amostras}

Foram coletadas 4 amostras de frutas (melão, mamão, melancia e abacaxi) em uma Unidade de Alimentação e Nutrição provenientes de um município da região do Cariri do Estado do Ceará. As amostras foram coletadas pela manhã e acondicionados em caixas isotérmicas com gelo e transportados para o Laboratório de Microbiologia de Alimentos da Faculdade de Tecnologia FATEC/ CENTEC Cariri. As análises foram realizadas em três repetições.

\section{Preparo das diluições decimais}

Em laboratório foram pesados $25 \mathrm{~g}$ de cada amostra de fruta, transferindo-as cada uma para $225 \mathrm{ml}$ de Água Peptonada (AP) a $0,1 \%$ (Diluente) seguido de homogeneização, correspondendo a diluição $10^{-1}$. Partindo da diluição $10^{-1}$, procederam-se as diluições decimais seriadas, $10^{-2}$, e $10^{-3}$, respectivamente.

\section{Análises microbiológicas}

As análises foram realizadas segundo os padrões e metodologias da Americam Public Health Association (APHA, 2001), descrita no Compendium of Methods for the Microbiological Examination of Foods. Para determinação de Coliformes totais e termotolerantes foram realizadas análises pelo método do Número Mais Provável (NMP. $\mathrm{g}^{-1}$ ), onde foi utilizada a técnica dos tubos múltiplos, em série de três tubos. Para o teste presuntivo, o meio de cultura utilizado foi o Caldo Lactosado Simples (CLS) e para o teste confirmativo o Caldo Lactose Bile Verde Brilhante (BVB-2\%). A partir das diluições previamente preparadas, ambas foram incubadas a $35^{\circ}-37^{\circ} \mathrm{C}$ por 48 horas em estufa bacteriológica. Considerouse como positivo os tubos que formassem gás no tubo de Durhan. Para o teste confirmativo de coliformes termotolerantes utilizou-se caldo EC (Escherichia coli), para repicagem das culturas dos tubos positivos (formadores de gás), sendo a temperatura de incubação $45^{\circ} \mathrm{C}$ por 24 horas. Para análise de Salmonella sp, a partir da diluição $10^{-1}$ retirou-se $1 \mathrm{~mL}$ onde foram adicionadas em tubos de ensaio contendo $9 \mathrm{~mL}$ de Tetrationato, posteriormente os tubos foram incubados em banho-maria por 24 horas a $45^{\circ} \mathrm{C}$. Após esse período, foram realizadas as semeaduras das amostras em placas de Petri bipartidas contendo Ágar Verde Brilhante e Salmonella sp, as placas foram incubadas em estufa a $37^{\circ} \mathrm{C}$ por 24 horas para a verificação da presença destes agentes.

\section{RESULTADOS E DISCUSSÃO}

Analisando-se a presença de Coliformes Totais e Fecais (CT e CF), as 4 amostras de frutas apresentaram contagem $\geq 2,4 \times 10^{3} \mathrm{NMP} / \mathrm{g}$ (Tabela 1 ), sendo que a Resolução RDC $\mathrm{N}^{\circ} 12$, de 2 de janeiro de 2001, do Ministério da Saúde (BRASIL, 2001), estabelece os padrões microbiológicos sanitários para alimentos, designados como: "frutas frescas, in natura, preparadas (descascadas ou selecionadas ou fracionadas), sanificadas, refrigeradas ou congeladas, para consumo direto", cuja tolerância máxima para amostra indicativa é de $5 \times 10^{2} \mathrm{NMP} / \mathrm{g}$ ou UFC/g de coliformes a $45^{\circ} \mathrm{C}$ e ausência de Salmonella sp em $25 \mathrm{~g}$ de amostra.

Vale salientar que não existe na legislação, padrões para bactérias mesófilas e coliformes totais, entretanto, de forma a padronizar, são preconizados que alimentos contento contagens microbianas da ordem de $10^{5}-10^{6} \mathrm{UFC} / \mathrm{g}$ são considerados impróprios para o consumo devido a perda do valor nutricional, alterações sensoriais, riscos de deterioração e/ou presença de patôgenos (AGÊNCIA NACIONAL DE VIGILÂNCIA SANITÁRIA, 2002).

Alguns autores obtiveram valores bastante semelhantes aos encontrados nesse estudo, como Palu et al., (2002) que avaliaram 15 amostras de frutas prontas para o consumo e encontraram duas amostras contaminadas com coliformes 
termotolerantes, sendo uma de mamão $\left(2,4 \times 10^{4} \mathrm{NMP} / \mathrm{g}\right)$ e outra de melão $\left(3,5 \times 10^{3} \mathrm{NMP} / \mathrm{g}\right)$. Pinheiro et al., (2005), detectaram em $28 \%$ das amostras de frutos minimamente processadas a presença de coliformes termotolerantes com valores superiores ao padrão estabelecido pela legislação, ou seja, superior a $5 \times 10^{2} \mathrm{NMP} / \mathrm{g}$.

Das 100 amostras de frutos minimamente processados analisados por Pinheiro, et al., (2005) dentre eles melão, mamão e abacaxi, 25 (25\%), estavam contaminadas com Salmonella sp e 28 (28\%), apresentavam coliformes termotolerantes em valores superiores a $5,0 \times 10^{2} \mathrm{NMP} / \mathrm{g}$, indicando que 43 amostras estavam impróprias para o consumo humano, segundo a $\mathrm{RDC} \mathrm{N}^{\circ} 12$ de 02 janeiro de 2001 (Brasil, 2001). A amostra de mamão formosa minimamente processada analisada apresentou a incidência de coliformes totais de $<3 \mathrm{NMP} / \mathrm{g}$ a 2,4 x $10^{6} \mathrm{NMP} / \mathrm{g}$ e coliformes termotolerantes foi $<3 \mathrm{NMP} / \mathrm{g}$ a $2,3 \times 10^{3} \mathrm{NMP} / \mathrm{g}$. Das 20 amostras de abacaxi minimamente processadas e analisadas, constatou-se a presença de coliformes totais e coliformes termotolerantes com valores entre $<3 \mathrm{NMP} / \mathrm{g}$ a $2,4 \times 10^{3} \mathrm{NMP} / \mathrm{g}$, resultado semelhante à amostra de abacaxi nesse estudo.

Segundo Soares (2013), a qualidade e a segurança dos alimentos minimamente processados estão intimamente relacionados à metodologia de processamento, qualidade da matéria prima, uso de embalagens apropriadas e às condições adequadas de armazenamento, sendo que a produção de alimentos seguros é responsabilidade de todos no sistema de produção.

A detecção de coliformes em alimentos são amplamente utilizados como indicadores de qualidade sanitária (USDA, 2012), assim, os resultados mostraram possíveis falhas no processo de higienização. Outros fatores agravantes podem ser também os responsáveis por tais resultados, como a qualidade da água de higienização desses frutos, o aspecto do ambiente em que as frutas são expostas em bandejas embaladas com plástico filme em balcões não refrigerados ou seja, à temperatura ambiente, podendo ter o contato assim com vários contaminantes como mãos dos trabalhadores e dos manipuladores e até mesmo a contaminação por vetores e pragas urbanas oriundas das áreas adjacentes, não seguindo assim o conjunto de medidas chamado Boas Práticas de Fabricação (BPF), o qual é considerado um dos programas mais importantes para se garantir a qualidade final de um produto.

Além desses fatores, existe a possibilidade dos frutos terem sido adquiridos pelo estabelecimento já contaminados, levando-se em consideração as fases do plantio, colheita, condições do transporte e armazenamento igualmente inadequados.

Tabela 1- Resultados microbiológicos obtidos para as frutas analisadas

\begin{tabular}{lccc}
\hline Amostra & Coliformes Totais $\left(\mathbf{3 5}^{\circ} \mathbf{C}\right)$ & Coliformes Termotolerantes $\left(\mathbf{4 5}{ }^{\circ} \mathbf{C}\right)$ & $\begin{array}{c}\text { Salmonella sp } \\
(\mathbf{e m} 25 \mathrm{~g})\end{array}$ \\
\hline Melão & NMP/g*** & NMP/g** & Ausente \\
Mamão & $\geq 2,4 \times 10^{3}$ & $\geq 2,4 \times 10^{3}$ & Ausente \\
Melancia & $\geq 2,4 \times 10^{3}$ & $\geq 2,4 \times 10^{3}$ & Ausente \\
Abacaxi & $\geq 2,4 \times 10^{3}$ & $\geq 2,4 \times 10^{3}$ & Ausente \\
\hline
\end{tabular}

**NMP/g: Número Mais Provável por grama.

\section{CONCLUSÕES}

Observando os resultados, que não foram satisfatórios, as amostras de frutas minimamente processadas encontram-se impróprias para o consumo, indicando que os produtos foram adquiridos, processados ou conservados de maneira inadequada.

Portanto, esses vegetais minimamente processados necessitam de cuidados quanto à sua higienização para evitar contaminações microbiológicas, sendo considerado essencial que revejam as Boas Práticas de Fabricação (BPF), assim como a adoção de um Programa de Análise de Perigos e Pontos Críticos de Controle (APPCC), objetivando o controle da higiene e da qualidade dos produtos recomendado pela Organização Mundial de Saúde, almejando atentar-se para possíveis etapas de contaminação e para garantir um produto saudável e seguro para o consumidor.

\section{REFERÊNCIAS BIBLIOGRÁFICAS}

AGÊNCIA NACIONAL DE VIGILÂNCIA SANITÁRIA. Resolução - RDC n.12, de janeiro de 2002. Disponível em: <http: //www.anvisa.gov.br/legis/resol/1201 rde.htm>. Acesso em: 21 jan. 2015.
ANDRADE, P. F. de S.; SEAB - Secretaria de Estado da Agricultura e do Abastecimento. DERAL Departamento de Economia Rural, 2012. Disponível: <http://www.agricultura.pr.gov.br/arquivos/File/deral/Pr ognosticos/fruticultura_2012_13.pdf $>$. Acesso em: 10 dez. 2014.

APHA. American Public Health Association. Compendium of the methods for the microbiological examination of foods. 4th. Washington, 2001. $676 \mathrm{p}$.

ARVANTOYANNIS, I. S;ROUHAS, P. Irrr Adiation applicationx in vegetables ande fruits: a review. Crit. Rev. Ood Sci. Nutr., v. 49, n. 5, p. 427-462, 2009.

BRASIL, 2001. ANVISA- Agência Nacional de Vigilância Sanitária. Resolução RDC n. 12 de 02 de janeiro de 2001 on line. Regulamento técnico sobre padrões microbiológicos para alimentos. Disponível em: http://e-legis.bvs.br>. Acesso em: 03 dez. 2014.

FENNEMA, O.R; DAMODARAN, S.; PARKIN, K.L. Química de Alimentos de Fennema. 4. Ed. Porto Alegre: Artmed, 2010. 
FOOD AND AGRICULTURE ORGANIZATION OF THE UNITED NATIONS- FAO. FAO Statistical Yerbook (2013). Disponível em: <http://issuu.com/faooftheun/docs/syb2013issuu/156>. Acesso em: 29 nov. 2014

JACXSENS, L.; LUNING, P.A; VAN DER VORSR, J.G.A.J. et al. Simulation modelling and risk assessment as tools to identify the impact of climate chance on microbiological food satety and case study of fresh produce suplly chain. Food Research International, v. 43, 1925-1935, 2010.

PALU, A. A.; TIBANA, A.; TEIXEIRA, L. M., MIGUEL, M. A. L., PYRRHO, A. S.; LOPES, H. R. Avaliação microbiológica de frutas e hortaliças frescas, servidas em restaurantes self-service privados, da Universidade Federal do Rio de Janeiro. Hig. Aliment., São Paulo, v. 16, n. 100, p. 67-71, 2002.

PINHEIRO, N. M. S. et al. Avaliação da qualidade microbiológica de frutos minimamente processados comercializados em supermercados de Fortaleza. Rev. Bras. Frut., Jaboticabal - SP, v. 27, n. 1, p. 153-156, abr. 2005.

RAMOS, B.; MILLER, F.; BRANDÃO, T. R. S.; TEIXEIRA, P.; SILVA, C. L. M.; Fresh fruits and vegetables- An overview on applied methodologies to improve its quality and safety. Innov Food Sci Emerg Tech. 2013; 20(0):1-15.

ROMANICHEN, C.; ZIROLDO, D. F.; SANTOS, R. A. M.; SOUZA, L. B. G. Avaliação higiênico- sanitária de alimentos minimamente processados. Mostra Interna de Trabalhos de Iniciação Científica. Out. de 2010. CESUMAR - Centro Universitário de Maringá- Paraná. Disponível em: <http://www.cesumar.br/prppge/pesquisa/mostras/quin mostra/cristiane_romanichen.pdf $>$. Acesso em $20 \mathrm{dez}$. 2014.

SOARES, N. F. Efeito da embalagem na conservação de pro- dutos minimamente processados. Anais. ViçosaMG, 2013. Disponível em: <htp:/www.cnph.embrapa.br/novidade/eventos/semipos/ texto10.pdf>. Aceso em 02 dez. 2014.

UNITED STATES DEPARTAMENT OF AGRICLTUREUSDA. Introduction to the microbiology of food processing. Small Plant. Food Safety and Inspection Service, 63 p., 2012. 